\title{
Relação professor e estudante na universidade: um olhar sobre a formação permanente e a atuação profissional ${ }^{1}$
}

\author{
Fabrício Oliveira da Silva²
}

Rosaria da Paixão Trindade ${ }^{3}$

\section{Resumo}

O texto objetiva analisar o que afirmam os docentes universitários sobre: i) as necessidades de realizar formação permanente; ii) o desenvolvimento de estratégias de ensino com vistas à promoção de aprendizagens nos estudantes; iii) a disponibilidade dos docentes em auxiliar os discentes que apresentam dificuldades de aprendizagem. A pesquisa revela os resultados de um questionário do tipo survey, aplicado a 338 professores universitários. O estudo permitiu concluir que a relação professor e estudante é fundamental para o desenvolvimento de aprendizagens. Os resultados revelam que os professores variam a metodologia de ensino de acordo com as especificidades do conteúdo a ser ensinado. De igual modo, ensinam estratégias que facilitam o aprendizado dos estudantes.

Palavras-chave: Perfil Profissional Docente; Relação Professor e Estudante; Atuação Profissional; Educação Superior.

\section{Relación maestro y estudiante en la universidad: Una mirada a la educación continua y el desempeño profesional}

\section{Resumen}

El texto tiene como objetivo analizar lo que dicen los profesores universitarios sobre: i) las necesidades para realizar una formación permanente; ii) el desarrollo de estrategias de enseñanza con miras a promover el aprendizaje en los estudiantes; iii) la disponibilidad de profesores para ayudar a los estudiantes que tienen dificultades de aprendizaje. La investigación revela los resultados de un cuestionario de encuesta, con 33 preguntas, aplicado a 338 profesores universitarios. El estudio concluyó que la relación entre profesor y alumno es fundamental para el desarrollo del aprendizaje. Los resultados revelan que los docentes varían la metodología de enseñanza de acuerdo con las especificidades del contenido a ser enseñado. Asimismo, enseñan estrategias que facilitan el aprendizaje de los estudiantes.

Palabras clave: Perfil Profesional Docente; Relación Profesor-Alumno; Actuación Profesional; Educación Superior.

\section{Introdução}

A relação professor e estudante tem sido uma temática de interesse por parte de professores e pesquisadores da educação, preocupados com os processos de desenvolvimento

\footnotetext{
${ }^{1}$ Trabalho oriundo de pesquisa financiada pelo Conselho Nacional de Desenvolvimento Científico e Tecnológico - CNPq. Pesquisa foi devidamente submetida e aprovada por Comitê de Ética em Pesquisa - CEP.

2 Pós-Doutor e Doutor - UNEB. Professor Adjunto da Universidade Estadual de Feira de Santana, de Feira de Santana, fosilva@uefs.br.

${ }^{3}$ Doutora - UFBA. Professora Adjunta da Universidade Estadual de Feira de Santana, de Feira de Santana, rosapt@uefs.br.
} 
de ensino e de aprendizagem na universidade. Não são raras as queixas de estudantes sobre a pouca aproximação que têm desenvolvido com os professores no espaço universitário. As razões são as mais diversas, mas se sobressaem aquelas que evidenciam que são os professores que pouco permitem a aproximação dos estudantes. A consequência disso, muitas vezes, está relacionada a problemas de aprendizagem dos estudantes.

O modo como o professor e o estudantes se relacionam na universidade, seja individual ou coletivamente, influencia no processo de desenvolvimento de aprendizagens dos estudantes, pois, de algum modo, isso interfere na forma como os discentes realizam suas atividades e, por conseguinte, em como se relacionam entre si. Assim sendo, essa relação na universidade demanda um processo de relações interpessoais que, de acordo com Moscovici (1985), são interações humanas que ocorrem permanentemente entre as pessoas através de comportamentos manifestos e não-manifestos, verbais e não-verbais, pensamentos, sentimentos, reações mentais e/ou físico-corporais.

Tais relações são fundantes para a promoção dos processos de ensino e de aprendizagem, sobretudo pela viabilidade dos mecanismos de confiança que aí se estabelecem. $O$ estudante universitário, principalmente os que estão nos primeiros semestres de curso, precisam transpor barreiras no campo das relações universitárias, caso desejem êxito no percurso formativo que vivenciam no cotidiano da instituição. São relações múltiplas e complexas que vão desde as que se estabelecem com os colegas de turma, com os professores em sala de aula, àquelas inerentes às pessoas que lidam e atuam na coordenação de colegiados, direção de departamentos, setores outros, como bibliotecas, laboratórios, Pró-Reitorias etc. O estudante precisa conviver com diversas pessoas no âmbito universitário e aprender com cada uma delas a funcionalidade do ambiente acadêmico, extraindo daí possibilidades de aprender e de identificar-se com o conhecimento que se produz e emerge de tais relações.

Por outro lado, os professores devem criar condições relacionais com os estudantes, com o objetivo de que estes possam compreender a dinâmica do trabalho educativo na universidade, sobretudo pela clareza que deve se instaurar nos princípios pedagógicos de que lançam mão, os professores, para desenvolver aprendizagens. Nessa direção, a relação pedagógica que se principia, por essa dinâmica, aponta para uma condição de que o discente possa desenvolver filiação acadêmica, com condições de compreender as funcionalidades das regras institucionais 
e, de igual modo, aprender o ofício de ser estudante, mobilizando os professores a engajaremse, cada vez mais, com o ofício de ser professor. Isso implica reconhecer que a relação entre professores e estudantes desenvolve condições de aprendizagens num processo de ambivalência, em que tanto se engajam e aprendem, os professores e os estudantes.

Há contextos em que, na atuação da docência, o professor universitário se sente inseguro em relação ao papel de mediador do processo, de ser o mobilizador de questionamentos, reflexões e ressignificações de conteúdos e, portanto, sente-se inseguro, também, em relação à sua condição de ajudar os alunos a desenvolverem a capacidade de pensar e argumentar, que a nova realidade exige (SANTOS; SOARES, 2011). Isso pode ser decorrente dos processos de formação pelos quais os professores vivenciam. Não basta, apenas, a formação inicial ou a continuada no âmbito da pós-graduação. É preciso que os professores invistam em uma formação permanente que seja articuladora dos processos de atuação profissional e de vivência do fazer universidade, demandada pelos acontecimentos cotidianos do exercício profissional docente.

Segundo Suñe, Araújo e Urquiza (2015), o professor universitário precisa conviver, diariamente com três dimensões da profissão: (i) a que tem relação com os conhecimentos específicos da área; (ii) a que se relaciona com os processos de gestão universitária, ou seja, condução de grupos, laboratórios, emissão de relatórios e pareceres etc.; (iii) a que implica o domínio da didática, conhecimento dos princípios do ensino e da aprendizagem. Esse domínio da didática requer, além da vivência e experiência, uma formação que atenda às necessidades formativas do docente, às necessidades de aprendizagem dos estudantes, bem como às demandas da sociedade, em relação aos egressos. Isso implica em se reconhecer que a vivência diária do professor consagra-se como uma formação permanente, que ele próprio vai construindo nos percursos de sua atuação profissional.

Trata-se, segundo Imbernón (2009), de uma formação que se tece no cotidiano e dilema da profissão, das acontecências do fazer educativo de cada docente. Esse tipo de formação requer que as ações partam dos problemas que circundam as instituições educacionais, com foco nas problematizações da prática, do fazer dos professores, logo dos modos próprios com que realizam a docência na universidade, em estreita relação com os estudantes. Além disso, a formação precisa estar acompanhada de mudanças contextuais, que nasçam das demandas 
cotidianas do trabalho docente. São aspectos que precisam ser pensados pelo docente que se disponibiliza a realizar uma formação que não seja pontual e que não se limite a obtenção de uma certificação para progressão na carreira. É, portanto, uma formação que se articula aos objetivos do desenvolvimento profissional e pessoal do professor, em que as preocupações se efetivam na relação com o estudante e com suas demandas na universidade.

Quando os professores se disponibilizam e investem em sua formação permanente, eles se tornam protagonistas do seu próprio fazer, pois a formação passa a ser tecida dentro do contexto social e profissional em que atuam na universidade. Assim sendo, o que possibilita o engendramento desse tipo de formação são as insurgências do fazer educacional na universidade, a partir do qual a relação professor e estudante se torna ainda mais fundante. Trata-se de uma formação que se dá em rede, não nas teias da individualidade, mas na preocupação com o outro, na coletividade. Nessa direção é que Imbernón (2009) considera vital, na formação permanente, criar dimensões de uma colaboratividade por meio da qual possa haver "uma forma de combater esse isolamento e individualismo [...] é a formação colaborativa[...]" (IMBERNÓN, 2009, p.65). Logo, há de ser um tema tratado no âmbito dos cursos, mas, sobretudo, tratado no âmbito institucional.

Mesmo discutindo as novas tendências da formação de professores, Imbernón (2009) em obra intitulada: formação permanente do professorado, com foco na educação básica, constrói relevante reflexões sobre os contextos formativos, a fim de se pensar a formação dos professores no/pelo cotidiano do trabalho que exercem na universidade. Para o referido autor, a formação leva em consideração os atos relacionais entre os agentes educativos, sobretudo, quando se leva em conta a preocupação com os processos de aprendizagem, sejam dos estudantes ou dos próprios professores. Em particular discussão, Imbernón (2009) faz uma distinção entre individualismo e individualidade, que muito é pertinente aos contextos da prática docente na universidade. Segundo o referido autor, a formação permanente deve assentar-se nos princípios da individualidade, entendida como contextos singulares da docência. Nesse aspecto, nega-se o individualismo, pois essa prática ofusca a dimensão da colaboratividade e do processo relacional, tão necessários para o desenvolvimento de aprendizagens na universidade.

Nesse contexto discursivo, a formação permanente torna-se relevante para que se entendam as ações educativas de professores universitários, frente à necessidade de que a 
prática de ensino esteja mobilizada pelas condições de se desenvolver estratégias que favoreçam a aprendizagem dos estudantes. O foco do ensino, numa dimensão epistemológica, em que o aprender é um princípio colaborativo da relação professor e estudante, potencializa-se quando o professor se insere numa formação permanente, em que se coloca como conhecedor e sujeito crítico e reflexivo de sua própria prática. Sentir-se capacitado a ajudar o aluno a aprender, nessa pesquisa, é entendido como um movimento que o docente faz ao ter condições de trabalho e de formação para tal. Parte-se do pressuposto de que o ensino se dá a partir da imersão num processo de formação, que demanda uma compreensão, assim como afirmam Wahlbrinck e Pacheco (2016, p.23) de que "o Ensino não se caracteriza com o simples ato de transferir conhecimentos por aqueles que sabem àqueles que não sabem". Assim, é preciso que a formação seja uma constante e que esteja na base das preocupações dos professores.

Com o objetivo de analisar o que afirmam os docentes universitários sobre as necessidades de realizar formação permanente; sobre o desenvolvimento de estratégias de ensino com vistas à promoção de aprendizagens nos estudantes; e sobre o que dizem os docentes sobre a disponibilidade de auxílio a discentes que apresentam dificuldades de aprendizagem, o presente estudo traz à baila os resultados de uma pesquisa desenvolvida por um grupo de pesquisadores de uma instituição pública de ensino superior. O estudo buscou mapear o perfil socioidentitário de docentes que atuam em diferentes áreas do conhecimento na Universidade Estadual de Feira de Santana (UEFS), bem como apresentar os resultados quantitativos a partir de quatro dimensões que transversalizam o fazer pedagógico dos professores. Nessa perspectiva, analisam-se questões inerentes a procedimentos que professores utilizam para evidenciar a necessidade de realizar formação permanente, de variar sua metodologia diante das necessidades educacionais dos estudantes, de desenvolver estratégias que facilitem a aprendizagem dos estudantes, e, por fim, mas não menos importante, de sentir-se capacitado para ajudar os estudantes com mais dificuldades.

Apesar de ser uma pesquisa que se desenvolve com foco na relação professor e estudante na universidade, mapeando o que ambos dizem sobre os processos de ensino e aprendizagem, o presente estudo foca nas respostas dadas por 338 professores participantes da pesquisa. 0 texto está dividido em quatro outras seções, além da introdução, na qual se apresentou a problemática e o objetivo do estudo. Assim sendo, a segunda seção do texto dedica-se a 
apresentar a tessitura metodológica em que se desenvolveu a presente pesquisa, com foco especial para o processo de construção e organização do questionário. Na terceira, abordam-se os resultados encontrados no questionário, tecendo o movimento de análise considerando-se os dados relativos ao tipo de vínculo, regime de trabalho e tempo de atuação na docência universitária. Na quarta seção, discorre-se sobre os dados inerentes à formação permanente e estratégias de ensino e de aprendizagem. Por fim, mas não de menor relevância, apresenta-se as considerações finais.

\section{Percurso metodológico}

A pesquisa se inscreve na epistemologia de natureza quali-quantititativa, segundo o que preconiza Creswell (2007), por considerar que este tipo de pesquisa ancora características tanto da pesquisa quantitativa, como da qualitativa, gerando um novo modo de realizar estudos em que pese a viabilidade de se trabalhar tanto com os dados numéricos, quanto com os textos que podem ser produzidos pelos colaboradores de uma pesquisa. Cabe ressaltar que o recorte para esse trabalho tem uma maior centralidade na epistemologia da pesquisa quantitativa, em que se apresentam as porcentagens considerando variáveis de frequência nas respostas dos colaboradores, valorizando a análise a partir das maiores ocorrências encontradas.

Como dispositivo de recolha de informações, a pesquisa se desenvolveu a partir de um questionário elaborado por um grupo de pesquisadores e estudantes da docência universitária, que desenvolvem a pesquisa intitulada Relação professor e estudante na universidade ${ }^{4}$. Trata-se de um questionário construído pelas relações dialógicas tecidas por professores e estudantes integrantes de grupo de pesquisa. Assim sendo, a construção do instrumento teve como base as acontecências da sala de aula na universidade, com foco nas práticas educativas de professores face ao desafio de promover condições de aprendizagem pelas relações pedagógicas que os docentes estabelecem com os estudantes na universidade. Nesse sentido, e buscando fazer emergir o vivido pelo professor no cotidiano da docência, as questões voltaram-se para mapear

\footnotetext{
${ }^{4}$ Pesquisa financiada pela Chamada Universal MCTI/CNPq n28/2018. Ressalte-se que a pesquisa foi submetida e aprovada pelo Comitê de Ética em Pesquisa da Universidade Estadual de Feira de Santana (UEFS), lócus em que se realizou a presente pesquisa.
}

Periódico Horizontes - USF - Itatiba, SP - Brasil - e021056 
como os professores desenvolvem as relações pedagógicas com os estudantes., refletindo situações do dia a dia da profissão. O questionário foi aplicado durante o mês de abril de 2020, através da plataforma Google forms. Nessa dinâmica, criou-se um link para acesso ao questionário, o qual foi enviado, por e-mail, para todos os diretores de departamentos da universidade, com solicitação de que se replicasse a todos os professores lotados em cada departamento. De um total de 982 professores da instituição, 338 acessaram e responderam às questões, o que representa uma amostra de um terço do universo de docentes da universidade.

Obteve-se a resposta de docentes de diferentes áreas do conhecimento da Universidade Estadual de Feira de Santana, que voluntariamente acessaram o questionário e responderam as 33 questões, sendo 08 inerentes ao perfil socioidentitário e profissional, e 25 relativas a situações pedagógicas vivenciadas pelos professores na universidade. O questionário foi elaborado considerando situações relatadas pelos professores e estudantes pesquisadores no que tange às vivências relacionais pedagógicas no âmbito de situações do planejamento, da produção de estratégias de ensino, da avaliação educacional e dos investimentos que docentes fazem na formação continuada. Com relação aos aspectos do perfil socioidentitário e profissional, as opções buscaram mapear idade, sexo, cor/raça, tipo de vínculo institucional, regime de trabalho, anos de atuação na docência no Ensino Superior e anos na docência em outros níveis.

Para este texto, fez-se o recorte para analisar as questões do perfil sócioidentitário, relativas ao tipo de vínculo dos professores, regime de trabalho na instituição e informações relativas aos anos de experiência na docência do ensino superior. Quanto às questões relativas às situações pedagógicas, analisou-se os dados inerentes às metodologias de ensino, formação permanente, estratégias de aprendizagem e capacitação para lidar com estudantes que apresentam dificuldades.

Estruturadas conforme os princípios de uma escala Likert ${ }^{5}$, as questões foram compostas de afirmações, seguida das alternativas: nunca, às vezes, frequentemente e sempre. Diante dessas quatro opções, o participante só poderia marcar apenas uma. Essa é uma escala que é bastante útil para analisar o comportamento das pessoas diante de um dado fenômeno. No

\footnotetext{
5 A escala Likert foi desenvolvida pelo cientista Rensis Likert. Trata-se de uma escala utilizada em estudos quantitativos em que o informante elege o grau de concordância ou discordância sobre informações que Ihe são apresentadas, escolhendo, para dada situação, um ponto numa escala com quatro ou cinco gradações. Em nosso estudo as gradações foram: nunca, às vezes, frequentemente e sempre.
} 
campo da educação, é uma escala de referência para se compreender os níveis de frequência com que os professores se comportam diante de situações de natureza pedagógica, e no caso da pesquisa em tela, também de natureza relacional. As afirmações se originaram, no presente estudo, de crenças comportamentais que são comumente visibilizadas no âmbito das salas de aula na universidade. Assim, as crenças revelam as atitudes que os professores adotam na relação com o estudante diante do desafio de ensinar e de possibilitar aprendizagens.

Nessa direção analítica, a atitude é uma característica das pessoas que faz referência ao conjunto de crenças sobre algo e sua resposta em relação a isso (THURSTONE, 1928). Aferir uma atitude pedagógica no campo da docência universitária se torna importante pelo fato de que este conhecimento é útil na compreensão do comportamento relacional que professores e estudantes estabelecem na universidade, e de como isso tem relação com os processos de ensino e de aprendizagem. É uma interessante pista para se desenvolver entendimentos sobre as formas como professores e estudantes tomam decisões para ensinar e aprender na universidade, revelando conhecimento do modo como se organizam pedagogicamente as relações entre esses sujeitos no âmbito da docência universitária.

\section{Perfil sócio profissional: tipo de vínculo, regime de trabalho e anos de experiência no ensino superior}

Ao analisar os dados referentes ao tipo de vínculo, tem-se um total de $92 \%$ de professores efetivos, caracterizados pelo vínculo permanente com a universidade. Registra-se, apenas, 6,8\% de professores na categoria de substituto, e 1,2\% de visitantes. Essas duas últimas categorias, caracterizam-se por um vínculo temporário, que conforme o Estatuto do Magistério Superior do Estado da Bahia, são vínculos em que o professor pode permanecer até 4 anos na instituição, podendo realizar novo processo de seleção e continuar por mais um período de 4 anos. No caso dos professores substitutos, o art. $2^{\circ}, \S 1^{\circ}$ da Lei 8.745 e art. 14 , incisos I a IV do Decreto 7.485/2011 definem condições para a existência de professores substitutos no âmbito da universidade (BAHIA, 2011).

Além de mapear o tipo de vínculo do docente, a pesquisa buscou identificar o regime de trabalho. Segundo a Lei № 8.352 , de 02 de setembro de 2002, no que preconiza sobre o Estatuto 
do Magistério Público das Universidades do Estado da Bahia, o regime de trabalho dos professores enquadra-se em três distintas modalidades: 20 horas semanais, 40 horas e 40 horas com Dedicação Exclusiva. No que se refere a essa última modalidade, o professor deve desenvolver projetos de pesquisa e/ou extensão e manter vínculo apenas com a instituição (BAHIA, 2002). Os dados referentes ao regime de trabalho mostram que 60\% dos professores estão no regime de dedicação exclusiva. Com 20h semanais, registram-se, apenas, 3\% dos participantes.

Quando se comparam os dados da UEFS com os que o Instituto Nacional de Pesquisas e Estudos Educacionais Anísio Teixeira (INEP) apresenta, em relação ao ano de 2019, (BRASIL, 2020), no que tange ao percentual de docentes do ensino superior em regime integral de trabalho, registra-se, conforme mapeamento do referido instituto, um total de $86,2 \%$ dos professores que possuem regime de trabalho por Dedicação Exclusiva. Na UEFS o total de docentes neste regime é de $60 \%$. Esse dado indica que nas instituições públicas tem sido crescente o número de professores que são efetivos e que trabalham em regime integral. Tal situação indica que na UEFS a maioria dos docentes é de categoria efetiva e com regime integral de trabalho, caracterizado pela dedicação exclusiva.

Isso implica no fato de que a relação professor e estudante é potencializada pela condição de professores manterem atividades em considerável carga horária de trabalho, sobretudo pela inserção de estudantes em projetos de pesquisa e de extensão, uma vez que os professores em regime de dedicação exclusiva precisam, obrigatoriamente, realizar tais projetos na composição de sua carga horária. Entende-se que nessa prática profissional abre-se espaço para implementação de ações de formação permanente, em serviço, pois os docentes costumam investir numa situação de trabalho docente, que se desenvolve pelas condições, inclusive, de militar temporalmente no exercício da profissão, tendo a carreira e o regime de trabalho como possibilidades de potencialização da formação em serviço. Segundo Tardif (2002), os saberes, conhecimentos construídos pelos professores são temporais, plurais e heterogêneos, personalizados e situados. Isso porque são construídos ao longo da trajetória profissional na instituição, fato para o qual, também, se consideram os regimes de trabalho dos professores bem como seus vínculos com a instituição.

Em matéria da docência universitária, há uma significativa problemática em torno da formação dos professores para a atuação profissional, sobretudo para aqueles que exercem a 
docência e não realizaram um curso de licenciatura (ANASTASIOU, 2002). A aprendizagem da docência, passa, muitas vezes, pelas aprendizagens experienciais logradas pelas acontecências do cotidiano (SILVA; ALVES, 2020), em que as relações entre professor e estudante são, também, determinantes para o desenvolvimento da docência na universidade. Se isso é verdade, é então verdadeiro que o tipo de vínculo e de regime de trabalho possibilitam maior vivência cotidiana da profissão, em que a instituição passa a ser compreendida como o espaço da formação, como o lócus de produção da autonomia do profissional. É no engendramento do seu fazer educativo que a formação permanente se apresenta como elemento que possibilita ao profissional sentirse muito mais desafiado e cobrado a investir na sua permanente formação, profissionalização, sobretudo para a produção de pesquisa, feito para o qual o tipo de vínculo e de regime de trabalho na instituição são determinantes.

Na pesquisa Relação professor e estudante na universidade, buscou-se, ainda, mapear o número de anos na docência dos professores no Ensino Superior. Assim sendo, perguntou-se, em intervalos temporais de cinco em cinco anos, o tempo de serviço dos professores. Os dados revelam que acima de 20 anos tem-se um total de 42,5\% dos participantes. Entre 16 a 20 anos, encontra-se 19\%, porcentagem que também foi igual para o intervalo entre 11 a 15 anos. Entre 5 a 10 anos tem-se 12,5\%, e entre 01 a 05 anos, apenas 9\%. Apesar de não poder concluir que o número de anos na docência esteja diretamente relacionado à qualidade do trabalho que os professores desenvolvem na universidade, é possível inferir que a temporalidade está intimamente relacionada ao desenvolvimento de práticas e saberes sobre a docência universitária, possibilitando, conforme assevera Tardif (2002), desenvolvimento de saberes, que são, também, construídos por uma temporalidade que atravessa a docência no Ensino Superior.

Na Educação Superior é mister que todo professor possa compreender que a sua formação profissional é constituída de modo perene, como um "continuum" que se estende por toda a vida profissional (FERREIRA, 2006; GÜNTHER; MOLINA NETO, 2000; MARCELO GARCÍA, 1995; PIMENTA, 2000; RANGEL-BETTI, 2001). Nessa direção, é possível pensar em uma formação que emerja, também, das vivências e experiências que o professor vai produzindo ao longo dos anos, não como um saber acumulado, como uma experiência relacionada a experimento, mas como uma experiência que revela as singularidades do processo de ensino que se efetiva, sobretudo, pelos modos de habitar a profissão docente na universidade. Tal ideia implica em 
reconhecer que o regime de trabalho, relacionado ao fato de ser e estar permanente na profissão, por anos consecutivos, cria para o docente a condição de um processo formativo que se fundamenta numa teoria tripolar da formação (PINEAU, 2004), em que os processos de auto, eco e heteroformação tornam-se centrais para o desenvolvimento dos saberes e experiência da docência.

Tal compreensão de formação pela temporalidade na docência universitária sugere que é possível, num processo formativo, compreender, circunscrever a produção dos sentidos que emergem sobre a formação, a partir da noção de que é o tempo o elemento vital para compreender como o movimento, neste caso, a formação, é tecido a partir da aferição que o tempo produz sobre o movimento. Logo, o movimento é um tempo que se singulariza, para cada um, ao produzir experiencialmente o movimento, numa compreensão do que este representa para si e para os outros, sobretudo no contexto desse estudo, que considera a relação entre professores e estudantes.

“O tempo diz respeito em primeiro lugar a todo poder que só se torna e permanece tal se conseguir ordenar e subordinar os múltiplos tempos dos outros ao seu próprio" (PINEAU, 2004, p.67). Assim, tem-se uma compreensão de que a formação se ancora no tempo próprio do sujeito, o que subordina o tempo dos outros ao seu próprio. Esta é uma forma do docente universitário assenhorear-se do seu próprio tempo, logo, de sua própria formação. Essa concepção encontra respaldo na crise da desregulação temporal contemporânea, demarcada pela esquizocronia 6 , que desenvolve uma nova concepção sociopolítica do tempo, que se pluraliza em diferentes tempos e em diferentes modos de concebê-lo. Tal condição faz emergir a compreensão de um tempo pessoal, individual e coletivo, que ganha espaço nos contextos das práticas universitárias, das relações entre professores e estudantes e da própria formação.

Não considerando o tempo de atuação da docência universitária como acumulativo de experiência, tem-se a insurgência de um outro tempo, caracterizado pela da aprendizagem experiencial da docência, que surge como marcador de sentidos para os processos de formação que se põem em movimento na condição de ser professor efetivo, trabalhar em regime de dedicação exclusiva e de portar anos na docência. Esse movimento gera as experiências que se

\footnotetext{
${ }^{6}$ Esse termo é trabalhado por Gaston Pineau (2004), em sua obra Temporalidades na formação e refere-se aos aspectos de multifacetários do tempo cronológico nas ações humanas.
}

Periódico Horizontes - USF - Itatiba, SP - Brasil - e021056 
produzem num tempo singular e que só pode ser aferido, medido e desmedido, pelo próprio professor. Isso não quer dizer que o tempo é o único elemento responsável pelo desenvolvimento de aprendizagens, mas aponta para o fato de que ele é um constructo relevante para entendermos o movimento de formação de um sujeito, que pode ter sentido ser compreendido pelo próprio docente, que o vive na essência de um movimento profissional em que a relação com o estudante e com a produção temporal de suas próprias experiências são fundantes no processo de formação contínua.

A teoria tripolar de formação constitui-se de três movimentos que são analisados por Pineau (2004), a partir da constituição de três prefixos, quais sejam auto-, hetero- e eco-, que se associam ao termo formação, produzindo diferentes perspectivas de entendê-la, a partir de si, do outro e do ambiente. A formação é, então, pensada como um ato relacional entre diferentes sujeitos, demarcando o lugar de uma aprendizagem que se processa com o outro. É a heteroformação que se constitui como uma forma de reconhecimento que o professor na relação com o estudante gesta, ao perceber que sua formação está implicada nas escolhas que faz, bem como pelos sentidos que produz a partir delas. Neste contexto, considera-se a relação com o outro como um modo de gerar aprendizagens que se efetivam pela inserção no ambiente universitário, que passa a ser, também, um elemento por meio do qual se produz a aprendizagem sobre a docência.

Com perspectivas de articular condições de pensar em paradigmas de formação que promovam o desenvolvimento profissional do docente, Candau (1997) enfatiza três eixos de investigação que se tornam relevantes para a compreensão de como a formação se dá no movimento experiencial. Segundo a referida autora, é preciso definir a escola, em nosso estudo a universidade, como o "lócus" da formação, não pelas vias de realização de cursos, mas pelo trabalho docente que aí se realiza. Assim, é preciso valorizar os saberes experienciais dos professores, principalmente os que emergem, em nossa concepção, dos processos de auto, eco e heteroformação; e, atentar para as diferentes etapas do desenvolvimento profissional docente. No que se refere ao último eixo, é pertinente destacar o fato de que a formação vai sendo tecida durante a vida profissional do docente, que é marcada por diferentes momentos e fases, apresentando características que diferencia o corpo docente em cada momento da carreira, o que Huberman (2000) denomina como ciclos de vida profissional do docente. 


\section{O que dizem os docentes sobre sua formação permanente e atuação profissional na universidade}

A expansão do ensino superior, no Brasil, sobretudo a partir da década de 1990, traz novas configurações para a estrutura organizacional das instituições de ensino superior, bem como apresenta um novo perfil dos estudantes. Esse novo cenário, segundo Santos; Trindade; Ribeiro (2012, p.14), "evidenciam [...] a necessidade das instituições investirem no desenvolvimento profissional de seus professores, diante dos desafios formativos interpostos à nova realidade, desafios esses, do mundo globalizado e específicos da dinâmica institucional local".

Ressalta-se, aqui, a importância do investimento em formação, no sentido de potencializar o conhecimento docente, no tocante à perspectiva didática. Importa que a instituição tenha uma política de formação docente, mas é preciso que os professores sintam a necessidade desta formação, bem como, sinalizem as suas necessidades formativas.

Esta pesquisa procurou saber dos professores sobre as suas necessidades, no que diz respeito à formação. Ao perguntarmos se sentem a necessidade de participar de cursos de formação docente, 32,2\% afirmaram sentir essa necessidade com pouca frequência e 3,3\% responderam nunca sentir essa necessidade. Os que responderam que frequentemente sentem necessidade de formação somam $28,1 \%$ e 36,4\% revelaram que sempre têm necessidade de formação. Os dados da pesquisa revelam uma contradição, no que diz respeito à participação em cursos de formação docente.

Apesar de $64,5 \%$ dos respondentes afirmarem que sempre ou frequentemente sentem necessidade de formação, apenas 8,3\% afirmam sempre participar de cursos de formação e $22,2 \%$ afirmam participar frequentemente. Os que participam às vezes ou nunca somam $69,5 \%$. Destaca-se, aqui, que os docentes afirmam ter necessidade, têm, na sua maioria, uma carga horária de trabalho de 40 horas semanais, com dedicação exclusiva, mas, esses mesmos docentes, raramente ou nunca participam de formação. Há de se considerar, no entanto, que em muitos casos as formações pouco dialogam com os saberes que os docentes desenvolvem em suas experiências de ensino. Quando não, tal saber é considerado inadequado.

Questionou-se se o modelo de formação da instituição atende as necessidades 
formativas dos professores. Entretanto, ressalta-se que a formação não se restringe ao âmbito da instituição onde trabalha, mas há um leque de opções em outros espaços. Ainda assim, o percentual dos que participam de formação é muito baixo.

Segundo Moraes (2008, p.34), é preciso "refletir sobre o enfoque tradicional que subsidia os trabalhos de formação docente, que com todos os seus vícios e estratégias, reproduzem um modelo de ensino de natureza tradicional". Entende-se, desta forma, que é preciso argumentar se o que, tradicionalmente, as instituições oferecem com proposta de formação atende às necessidades dos professores. O modelo de formação tradicional, que valoriza um único modelo epistemológico de ensino, não atende às novas exigências e configurações educacionais.

Entre essas novas configurações, destaca-se as novas demandas sociais, bem como o perfil dos estudantes que ingressam no ensino superior. Isso requer a adoção de diferentes estratégias de ensino e aprendizagem. Uma das pistas para entender a não participação de professores em cursos de formação, pode, entre outras razões, ser justificado pela pouca articulação entre os objetivos dos cursos oferecidos e o desenvolvimento das necessidades formativas para a prática profissional. Os elementos do cotidiano universitário tornam-se centrais nesse processo, visto que se faz necessário uma articulação entre os objetivos da formação com a prática profissional.

A escolha de estratégias deve levar em consideração os objetivos propostos em cada componente curricular. É preciso observar, ainda, se o perfil da turma se adequa às estratégias. Quando perguntados se os docentes variam a metodologia de ensino em função do tipo de conteúdo a ser ensinado, $43,2 \%$ dos professores responderam que o fazem sempre, $38,5 \%$ frequentemente, $17,2 \%$ dos respondentes sinalizaram que fazem essas adequações às vezes e $1,2 \%$ que nunca fazem.

Esses dados revelam que mais de $80 \%$ dos docentes se preocupam em adequar as estratégias ao conteúdo. No entanto, há cerca de $20 \%$ de docentes que não o fazem com frequência, ou não o fazem. Isso pode revelar que, para esses professores, o processo está centrado no ensino, sem uma estreita relação com a aprendizagem. É preciso, aqui, destacar alguns pontos que são relevantes: (i) o professor não varia as estratégias porque não quer ou porque não sabe fazer diferente? (ii) a sua formação, inicial ou continuada, abordou a temática de estratégias de ensino e aprendizagem? (iii) a instituição onde atua tem proposta de formação 
que aborde tal temática? (iv) ao escolher as estratégias, o professor foca na aprendizagem dos seus alunos? (v) o professor leva em consideração as necessidades formativas dos estudantes para reconfigurar seu ensino, buscando implementar novas tessituras de aprendizagem?

A postura do professor no processo de ensino e aprendizagem tem forte ligações com as teorias que, implicitamente, fundamentam a sua prática. De acordo com Alves e Pozo,

[...] essas teorias são chamadas implícitas, porque, apesar de direcionar as ações que respondem às situações de nossa vida cotidiana, são realizadas sem passar por um processo explicitamente consciente. São realmente resultados da experiência pessoal no ambiente cultural da aprendizagem, é algo que sentimos, vivemos e experimentamos e, portanto, são difíceis de serem compartilhados e modificados (ALVES; POZO, 2020, p.5).

Desta forma, os autores ressaltam que, de acordo com a teoria que a fundamenta, a prática pedagógica pode estar centrada no ensino ou na aprendizagem. Muitas vezes o docente não se dá conta da necessidade de ensinar aos estudantes estratégias que possam facilitar a aprendizagem. Os dados da pesquisa revelam que 3,6\% dos docentes nunca ensinam estratégias de aprendizagem aos seus alunos. $22,8 \%$ ensinam às vezes, $53 \%$ frequentemente e $20,7 \%$ sempre ensinam alguma estratégia. Este dado aponta para um ponto importante: muitas vezes os professores não atentam para a necessidade de ensinar alguns procedimentos e/ou estratégias na universidade.

Assinalou-se a importância de variar estratégias de ensino, mas, também a necessidade de ensinar estratégias de aprendizagem. Isso não quer dizer que o professor deva, a cada aula, trazer uma inovação. Mesmo porque o estudante precisa, em muitos casos, aprender a utilizar tais estratégias e isso requer tempo didático. Mas, uma única estratégia pode não contemplar a complexidade do processo de aprendizagem. É preciso ter clareza que os estilos de aprendizagem são diferentes, bem como as dificuldades enfrentadas pelos alunos.

Ao serem perguntados se se sentem capacitados para ajudar os alunos com mais dificuldade, $1,5 \%$ dos respondentes sinalizaram que não se sentem e $28,4 \%$ responderam que às vezes se sentem capacitados. Por outro lado, $42 \%$ revelaram que frequentemente e $28,1 \%$ sempre se sentem capacitados.

O professor, enquanto mediador do processo de ensino e aprendizagem precisa sentir-se 
capacitado para ajudar os estudantes que se encontram em dificuldades, visto que o propósito do processo é que os alunos aprendam. Muito fácil seria lidar apenas com estudantes que não têm dificuldades em aprender. Mas esta não é a realidade. Então, pensar em uma escola inclusiva não se restringe apenas a viabilizar o ingresso de todos, mas viabilizar a permanência de todos, com aprendizagem. Isso perpassa por um processo de formação e uma relação entre professor e estudantes onde há uma abertura para o diálogo, trocas e interações. Há de se considerar, o fato de que os professores, para tal feito, necessitam do apoio da instituição, uma vez que, segundo Hino (2019), é a instituição de ensino um espaço em que o aprendizado deve possibilitar uma formação que esteja relacionada a vida real. E isso significa que está na docência a condição para tal feito, desde que a instituição também possibilite condições e viabilidades aos professores, que também, necessitam porem-se em disposição.

Sentir-se capacitado a ajudar os estudantes, demanda entender que a ajuda significa disposição para estar em constante processo de formação, investindo tempo e disponibilidade didática para criar situações que mobilizem o estudante a aprender. Nesse sentido, percebemos que mais de $60 \%$ dos professores afirmam sentir-se frequentemente e sempre preparados para ajudar os estudantes com mais dificuldades. Resta, no entanto, saber de que dificuldades abordam os professores. Como essas dificuldades são mapeadas e transpostas em estratégias de ensino e de mobilização de aprendizagens? Questões como essas só serão conhecidas com a narrativa dos professores colaboradores, situação que se dará em outro momento deste estudo. O que abordou-se, aqui, no entanto, foram os resultados dos questionários, com foco nas porcentagens das respostas. A pesquisa continuará provocando a seguir produzindo diálogos e reflexões qualitativas com os professores, possibilitando que outras ampliações e esclarecimentos se façam presentes em estudos e textos posteriores.

\section{Considerações finais}

O estudo possibilita concluir que a docência universitária ainda se enreda numa problemática que tem a ver com a formação dos professores para o exercício profissional. Não ter, necessariamente, uma formação em nível de licenciatura implica na condição de se reconhecer que o professor universitário enfrenta desafios para habitar a profissão docente 
produzindo, seus saberes, práticas, vivências e experiências na relação cotidiana que estabelece com os estudantes. Assim, uma das formas de formação que se evidenciam, como emergentes no processo, demanda do modo experiencial como professores produzem suas táticas para sentir-se, entre outras ações, capacitados a ajudar os estudantes a aprenderem.

O saber experiencial tem seu valor nos processos relacionais, mas não figuram como modo único de construir processos formativos, que demandem o desenvolvimento de destrezas para o trabalho docente na universidade. Se esse saber não se consolidar como basilar para que os professores inovem e construam estratégias que potencializem o processo de aprendizagem dos estudantes, de pouca valia ele será. Nessa dinâmica, o estudo mostrou que a grande maioria dos professores informa produzir variações em suas estratégias de ensino, mobilizados pela perspectiva de atender as necessidades dos estudantes. Mas o dado não possibilita concluir que as estratégias estejam relacionadas a um processo formativo que tenha se originado das necessidades dos estudantes.

A docência universitária se constrói a partir de uma formação inicial e continuada, mas também através das experiências vivenciadas. Essas duas dimensões - formação e experiências são, sem dúvidas, determinantes para a relação que se estabelece entre professores e estudantes. As novas dinâmicas sociais requerem um investimento em formação de professores, visto que a universidade tem um novo e diverso perfil de estudantes, além de um compromisso com a formação inicial de diversos profissionais.

O investimento em formação deve ser uma responsabilidade institucional, mas não pode ser unilateral. O professor precisa identificar as suas necessidades e investir em uma formação continuada. Essa formação pode proporcionar uma melhor atuação profissional, bem como facilitar e/ou estreitar a relação entre professor e estudante.

Os dados da pesquisa revelam que os docentes reconhecem que têm algumas dificuldades e precisam de investimento em formação, sobretudo da formação gestada na própria autonomia reflexiva do docente, o que demanda uma formação continuada de natureza autoformativa. Entretanto, a grande maioria diz que não participa ou que pouco participa de cursos de formação continuada ofertada pela própria instituição, ainda que, na grande maioria, sejam professores com um regime de trabalho de 40 horas com dedicação exclusiva à instituição. Tal dado é paradoxal, pois um docente em tempo integral na instituição deveria ter, como 
prerrogativa basilar, a necessidade de investir em formações que possibilitassem impactos nas aprendizagens dos estudantes. Para além de crescimento na carreira, o que é possibilitada pela formação continuada, sobretudo pela realização de cursos de pós-graduação, deve êxito pedagógico integrar a base da preocupação dos docentes em relação ao seu processo formativo na universidade.

O início do exercício na docência, sobretudo para professores iniciantes, pode trazer certa insegurança e/ou sensação de despreparo. No entanto, observou-se que, nesta pesquisa, que mais da metade dos docentes tem acima de 15 anos no exercício do magistério superior. Esse período de experiência poderia significar um maior preparo para o ensino. Mas, cerca de 30\% dos professores sinalizaram que às vezes ou nunca se sentem com condições de ajudar os alunos com dificuldades. De algum modo, a pesquisa evidencia a necessidade de que a formação docente precisa ser pensada no âmbito institucional, mas sobretudo, ser pensada para atender as necessidades formativas docentes face aos processos relacionais que estabelecem com os estudantes na universidade, e, acima de tudo, ser um desejo dos professores. Mas, de fato, não é um desejo por qualquer formação, mas por formações que dialoguem diretamente com os saberes produzidos no cotidiano da docência que realizam na universidade.

Ao se analisar o conjunto de questões inerentes ao status profissional dos docentes e o modo como eles se relacionam com os estudantes, é possível concluir que a relação professor e estudante é fundamental para o desenvolvimento de aprendizagens. Os resultados revelam que os professores variam a metodologia de ensino de acordo com as especificidades do conteúdo a ser ensinado. De igual modo, ensinam estratégias que facilitam o aprendizado dos estudantes. No que tange aos aspectos da formação permanente, os dados mostram que os docentes sentem necessidade de realizar formação permanente, mas pouco o fazem.

\section{Referências}

ALVES, I. P.; POZO, J. I. Teorias implícitas de professores universitários de cursos de formação docente sobre dificuldades de aprendizagem. Revista Internacional de Formação de Professores (RIFP), Itapetininga, v.5, e020022, p.1-26, 2020. Disponível em: https://periodicoscientificos.itp.ifsp.edu.br/index.php/rifp/article/view/65/48. Acesso em: 01 maio 2021. 
ANASTASIOU, L. G. C. Construindo a docência no ensino superior: relação entre saberes pedagógicos e saberes científicos. In: ROSA, D. E. G., SOUZA, V. C. (orgs.). Didáticas e práticas de ensino: interfaces com diferentes saberes e lugares formativos. Rio de Janeiro: DP\&A, 2002. P. 173-187

BAHIA. Lei n. 8.352 de 02 de setembro de 2002. Estatuto do Magistério Público das Universidades do Estado da Bahia, Salvador, BA. set 2020.

BAHIA. Decreto n. 7.485 de 18 de maio de 2011. Estatuto do Magistério Público das Universidades do Estado da Bahia, Salvador, BA. set 2020.

BRASIL. Instituto Nacional de Estudos e Pesquisas Educacionais Anísio Teixeira (Inep). Censo da Educação Superior 2019: resumo Técnico. Brasília, 2020.

CANDAU, V. M. Formação continuada de professores: tendências atuais. In: CANDAU, V. M. (org.). Magistério: construção cotidiana. Petrópolis: Vozes, 1997. p. 51-68

CRESWEL, J. W. Projeto de pesquisa: método qualitativo, quantitativo e misto. 2. ed. Porto Alegre: Artmed, 2007.

FERREIRA, L. A. O professor de educação física no primeiro ano da carreira: análise da aprendizagem profissional a partir da promoção de um programa de iniciação à docência. 2006. 216f. Tese (Doutorado em Educação) - Faculdade de Educação, Universidade Federal de São Carlos, São Carlos, 2006.

GÜNTHER, M. C. C.; MOLINA NETO, V. Formação permanente de professores de educação física na rede municipal de ensino de Porto Alegre: uma abordagem etnográfica. Revista Paulista de Educação Física, São Paulo, v.14, n.1, p.85-91, 2000.

HINO, M. C. Desafios da educação na era da tecnologia. Trabalho \& Educação, v.28, n.1, p.127139, 2019. DOI: 10.35699/2238-037X.2019.9868. Disponível em:

https://periodicos.ufmg.br/index.php/trabedu/article/view/9868. Acesso em: 14 fev.2021.

HUBERMAN, M. O ciclo de vida profissional dos professores. In: NÓVOA, A. (org.). Vidas de professores. 2. ed. Porto: Porto, 2000. p.31-61.

IMBERNÓN, F. Formação permanente do professorado: novas tendências. São Paulo: Cortez, 2009.

MARCELO GARCÍA, C. A formação de professores: novas perspectivas baseadas na investigação sobre o pensamento do professor. In: NÓVOA, A. (org.). Os professores e a sua formação. Lisboa: Dom Quixote, 1995. p.51-76.

MORAES, M. C. Ecologia dos saberes, complexidade, transdisciplinaridade e educação: novos fundamentos para iluminar novas práticas educacionais. São Paulo: Antakarana/WHN - Willis

Periódico Horizontes - USF - Itatiba, SP - Brasil - e021056 
Harman House, 2008.

MOSCOVICI , F. Desenvolvimento interpessoal. 3. ed. Rio de Janeiro: LTC, 1985.

PIMENTA, S. G. Professor: formação, identidade e trabalho docente. In: PIMENTA, S.G (org.). Saberes pedagógicos e atividade docente. 2. ed. São Paulo: Cortez, 2000. p.15-35.

PINEAU, G. Temporalidades na formação. São Paulo: Triom, 2004.

RAMOS, R. A. R. S; TRINDADE, R. P.; RIBEIRO, M. L. Expansão do ensino superior: uma abordagem sobre a formação pedagógica de professores. In: COLÓQUIO INTERNACIONAL SOBRE GESTÃO UNIVERSITÁRIA NAS AMÉRICAS. 2012. Anais [...], Universidade Veracruzana: Veracruz-ME, 2012, p.1-17. Disponível em: https://repositorio.ufsc.br/handle/123456789/25876/browse?value=Trindade\%2C+Rosaria+da +Paix\%C3\%A3o\&type=author. Acesso em: 25 abr. 2021.

RANGEL-BETTI, I. C. Os professores de educação física atuantes na educação infantil: intervenção e pesquisa. Revista Paulista de Educação Física, Suplemento 4, São Paulo, p.83-94, 2001.

SANTOS, C. P.; SOARES, S. R. Aprendizagem e a relação professor-aluno na universidade: duas faces de uma mesma moeda. Est. Aval. Educ., São Paulo, v.22, n.49, p.353-370, maio/ago. 2011. Disponível em:_http://www.fcc.org.br/pesquisa/publicacoes/eae/arquivos/1641/1641.pdf. Acesso em: 25 abr. 2021.

SILVA, F. O.; ALVES, I. S. Contribuição do PIBID para a prática profissional: aprendizagens da docência por homologia na formação inicial. Revista Exitus, Santarém-PA, v.10, n.1, p.1-26, 2020, e020104. Disponível em: https://doi.org/10.24065/2237-9460.2020v10n1ID1499. Acesso em 25 abr. 2021.

SUÑE, L. S.; ARAÚJO, P.J. L.; URQUIZA, R. A. Desenho de currículo para desenvolver competências: uma proposta metodológica. Aracaju: EDUNIT, 2015.

TARDIF, M. Saberes docentes e formação profissional. Petrópolis: Vozes, 2002.

THURSTONE, L. L. Attitudes can be measured. American Journal of Sociology, v.33, n.4, p.529554, 1928.

WAHLBRINCK, I. F.; PACHECO, L. M. D. A extensão universitária sob o viés da ética do cuidado: possibilidade de práxis emancipatória. Horizontes, v.34, n.2, p.19-29, dez. 2016.

Recebido em maio 2021.

Aprovado em agosto 2021. 